\title{
Prevention is better than treatment: the case of Qatar
}

\author{
Ali H Mokdad ${ }^{1 *}$ and Alan D Lopez ${ }^{2}$
}

Keywords: Prevention, Qatar, Non-communicable diseases, Risk factors

"Prevention is better than treatment", says an old Arab proverb, yet unfortunately for many Arabs today, medical treatment is the main method of dealing with diseases and risk factors. In a recent Population Health Metrics publication, "The diabetes-obesity-hypertension nexus in Qatar: evidence from the World Health Survey", [1] Ali et al. analyzed data from the World Health Organization's World Health Survey conducted in Qatar in 2006. The findings revealed remarkably high prevalences of obesity (35.4\%), diabetes (16.4\%), and hypertension (18.7\%). These levels of established risk factors for major vascular diseases are all the more alarming in a young population. Indeed, the findings call for urgent and greatly strengthened non-communicable disease prevention as a priority in the country and, more broadly, in the region.

The study, admittedly, has some limitations. It is crosssectional and therefore not able to establish causation. Furthermore, it is possible that the authors may have overestimated the burden of chronic diseases and levels of risk factor exposure since survey nonrespondents may be healthier than respondents; in the Gulf region, individuals with medical conditions may be more likely to respond to health surveys for a number of reasons. Moreover, the study is based on data from 2006, although the timeliness of the data may not be as great a concern as initially thought. Qatar recently released the findings of its WHO STEPwise approach to surveillance of non-communicable diseases (STEPS) 2012 survey, which showed comparably high - if not even higher - levels of risk factor exposure for non-communicable diseases [2], with reported prevalences of $41.4 \%$ for obesity, $16.7 \%$ for diabetes, and $32.9 \%$ for hypertension. While the results from the two studies are

\footnotetext{
* Correspondence: mokdaa@uw.edu

${ }^{1}$ Institute for Health Metrics and Evaluation, University of Washington, 2301 5th Ave. Suite 600, Seattle, WA 98121, USA

Full list of author information is available at the end of the article
}

not directly comparable due to different methodologies (the World Health Survey included non-Qataris, while STEPS only included Qataris aged 18 to 64 years old), the new report suggests that key risk factors for noncommunicable diseases in Qatar are not improving and are at alarmingly high levels.

The study by Ali et al. provides new evidence on the distribution of risk factor exposures in Qatar that is important for guiding and focusing policy responses. They report, for example, that obesity is higher in urban areas. Rates of obesity, diabetes, and hypertension were higher among the Qatari population than the non-Qatari and among the poor compared to higher-income groups. Data from the STEPS 2012 study confirm that obesity, diabetes, and high blood pressure are strongly associated with physical inactivity and poor diet.

A recent study focusing on the burden of disease in the Arab world found that the increase in disease burden from non-communicable diseases and road injuries has been most dramatic in the high-income countries of the Gulf region [3]. Disability-adjusted life years (DALYs) from road injuries for these countries rose by $63 \%$ between 1990 and 2010, while DALYs from major depressive disorder, anxiety disorders, and low back pain increased by more than $100 \%$. The burden of diabetes increased by more than $200 \%$. Not all is doom and gloom, however; over the same period, the Gulf countries have collectively greatly reduced health loss from communicable and neonatal conditions. For example, preterm birth complications and lower respiratory infections, which ranked as the first- and sixth-leading causes of disease burden, respectively, in high-income Gulf countries in 1990, ranked sixth and 16th in 2010.

Rapid demographic changes in Qatar and the Gulf region are contributing to increases in the burden of noncommunicable diseases in the region. Mokdad et al. found 
that population aging alone accounted for $11.4 \%$ of the increase in DALYs from non-communicable diseases, with another $54.6 \%$ due to population growth. Nevertheless, increases in the incidence of major non-communicable diseases due to poor risk factor profiles have been responsible for a third of the increase in DALYs in the region. Qatar currently has a young population; unless the incidence of non-communicable diseases is attenuated, these demographic changes will lead to a higher burden from non-communicable diseases for health services to address.

The Global Burden of Diseases, Injuries, and Risk Factors Study 2010 (GBD 2010) identified that preventable risk factors have contributed most to the rise of premature death and disability from non-communicable diseases in the Gulf. Dietary risks, high blood pressure, smoking, high body mass index, and high fasting plasma glucose are among the top 10 risk factors in all three regional groupings of the Arab World (low income, middle income, and high income or Gulf countries). Indeed, the GBD 2010 findings underscore the value of implementing interventions to detect and treat high blood pressure and high fasting plasma glucose. A key priority to reverse the rising disease burden from non-communicable diseases in the Gulf is research to identify the most effective ways to strengthen prevention programs and to incentivize individuals to improve the quality of their diets, lose weight, and quit smoking.

The findings from Qatar published in Population Health Metrics should be an urgent wake-up call to action in the country, and for its neighbors. Qatar is a very rich country and has the means to develop, implement, and evaluate prevention and control programs for non-communicable diseases. Qatar can easily improve its health information systems to better track risk factors and their burden in the country through better organization, training, and application of established approaches, including rapidly strengthening procedures to collect, certify, and disseminate cause of death data, as other high-income countries have done [4]. There are opportunities for infrastructure improvements to increase physical activity and improve health. For example, as Qatar is preparing to host the World Cup in 2022, where athletes will have to compete in the hot summer weather, lessons learnt could be applied to facilitate greater exercise levels among the population at large. Providing a safe and a culturally appropriate place for physical activity may well encourage Qataris, both males and females, to be more physically active.

The collective findings of Ali et al., STEPS 2012, and GBD 2010 call for greater, more strategic efforts to prevent and control risk factors in Qatar. There is a need to move from a medical treatment approach to a prevention strategy, focusing on smoking, poor diet, and lack of physical activity. Prevention efforts need to involve other partners in the country besides the Ministry of
Health. Qatar and other Gulf countries might well benefit from working together to develop and implement strategies for preventing and controlling risk factors for non-communicable diseases.

While treating sick individuals should always be a priority, this cannot be at the expense of preventing diseases. A balance between what is immediate (treating sick individuals) and what is important (preventing illnesses) should be achieved. Resources and political will are crucial. It is time to give much greater emphasis to prevention in order to help Qataris live longer and healthier lives. Indeed, our ancestors were correct: prevention is better than treatment.

\section{Author details}

${ }^{1}$ Institute for Health Metrics and Evaluation, University of Washington, 2301 5th Ave. Suite 600, Seattle, WA 98121, USA. ${ }^{2}$ School of Population and Global Health, University of Melbourne, 207 Bouverie St., Level 5, Melbourne, VIC 3010, Australia.

Received: 5 August 2014 Accepted: 5 August 2014

Published: 28 August 2014

\section{References}

1. Ali F, Nikoloski Z, Reka H, Gjebrea O, Mossialos E: Diabetes-obesity-hypertension nexus in Qatar: evidence from the World Health Survey. Popul Health Metr 2014, 12:18.

2. Qatar STEPS Noncommunicable Disease Risk Factors Survey 2012. http://www.who.int/chp/steps/Qatar_FactSheet_2012.pdf.

3. Mokdad AH, Jaber S, Aziz MIA, AlBuhairan F, AlGhaithi A, AlHamad NM, Al-Hooti SN, Al-Jasari A, AlMazroa MA, AlQasmi AM, Alsowaidi S, Asad M, Atkinson C, Badawi A, Bakfalouni T, Barkia A, Biryukov S, El Bcheraoui C, Daoud F, Forouzanfar MH, Gonzalez-Medina D, Hamadeh RR, Hsairi M, Hussein SS, Karam N, Khalifa SEAH, Khoja TAM, Lami F, Leach-Kemon K, Memish ZA, et al: The state of health in the Arab world, 1990-2010: an analysis of the burden of diseases, injuries, and risk factors. Lancet 2014, 383:309-320.

4. Murphy SL, Xu J, Kochanek KD: Deaths: Final Data for 2010. Hyattsville, MD: National Center for Health Statistics; 2013 [National Vital Statistics Reports].

doi:10.1186/s12963-014-0021-1

Cite this article as: Mokdad and Lopez: Prevention is better than treatment: the case of Qatar. Population Health Metrics 2014 12:21.

\section{Submit your next manuscript to BioMed Central and take full advantage of:}

- Convenient online submission

- Thorough peer review

- No space constraints or color figure charges

- Immediate publication on acceptance

- Inclusion in PubMed, CAS, Scopus and Google Scholar

- Research which is freely available for redistribution 